\title{
Thirty-day readmissions in surgical and transcatheter aortic valve replacement: a systematic review and meta-analysis
}

Authors: Stein Ove Danielsen, PhDC, RN ${ }^{\mathrm{a}, \mathrm{b}, \mathrm{c}}$, Philip Moons, PhD, RN ${ }^{\mathrm{c}, \mathrm{d}}$, Irene Sandven, $\mathrm{MPH}, \mathrm{PhD}^{\mathrm{e}}$, Marit Leegaard, $\mathrm{PhD}, \mathrm{RN}^{\mathrm{f}}$, Svein Solheim, $\mathrm{PhD}, \mathrm{MD}^{\mathrm{g}}$, Theis Tønnessen, $\mathrm{PhD}, \mathrm{MD}^{\mathrm{b}}$, h , Irene Lie, $\mathrm{PhD}, \mathrm{RN}^{\mathrm{a}}$

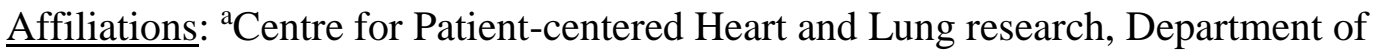
Cardiothoracic Surgery, Oslo University Hospital, Oslo, Norway, This author takes responsibility for all aspects of the reliability and freedom from bias of the data presented and their discussed interpretation, ${ }^{\mathrm{b}}$ Institute of Clinical Medicine, Faculty of Medicine, University of Oslo, Oslo, Norway, This author takes responsibility for all aspects of the reliability and freedom from bias of the data presented and their discussed interpretation, ${ }^{\mathrm{c}} \mathrm{KU}$ Leuven Department of Public Health and Primary Care, KU Leuven-University of Leuven, Leuven, Belgium, This author takes responsibility for all aspects of the reliability and freedom from bias of the data presented and their discussed interpretation, ${ }^{\mathrm{d}}$ Institute of Health and Care Sciences, University of Gothenburg, Gothenburg, Sweden, This author takes responsibility for all aspects of the reliability and freedom from bias of the data presented and their discussed interpretation, ${ }^{\mathrm{e} O}$ Oslo Centre of Biostatistics and Epidemiology, Oslo University Hospital, Oslo, Norway, This author takes responsibility for all aspects of the reliability and freedom from bias of the data presented and their discussed interpretation ${ }^{f}$ Department of Nursing and Health Promotion, Faculty of Health Sciences, Oslo Metropolitan University, Oslo, Norway, This author takes responsibility for all aspects of the reliability and freedom from bias of the data presented and their discussed interpretation, ${ }^{\mathrm{g}}$ Center for Clinical Heart Research and Department of Cardiology, Division of Medicine, Oslo University Hospital, Ullevål, Oslo, Norway, This author takes responsibility for all aspects of the reliability and freedom from bias of the data presented and their discussed interpretation, ${ }^{\mathrm{h}}$ Department of 
Cardiothoracic Surgery, Division of Cardiovascular and Pulmonary Diseases, Oslo University Hospital, Ullevål, Oslo, Norway, This author takes responsibility for all aspects of the reliability and freedom from bias of the data presented and their discussed interpretation

Corresponding author: Stein Ove Danielsen, Centre for Patient-centered Heart and Lung research, Department of Cardiothoracic Surgery, Oslo University Hospital, Building 63, Ullevål, Oslo, Pb 4956, Nydalen, 0424, Norway, Tel: +47-41368255; E-mail: steinda@ uio.no

Sources of funding: This project has been made possible by the Norwegian ExtraFoundation for Health and Rehabilitation, the Bergesen Foundation, and the Raagholt Foundation (all non-profit organizations). They had no role in any part of this study.

Disclosures: None of the authors have any connections with industry or financial associations that pose a conflict of interest in relation with this study. Conflict of interest: none declared. The authors report no relationships that could be construed as a conflict of interest

Keywords: Surgical aortic valve replacement, transcatheter aortic valve replacement, aortic stenosis, thirty-day readmission 


\begin{abstract}
Background

The 30-day all-cause readmission rate after surgical aortic valve replacement (SAVR) and transcatheter aortic valve replacement (TAVR) vary substantially. We conducted a systematic review and meta-analysis to examine the overall incidence, causes, and risk factors of 30-day all-cause readmission rate after SAVR and TAVR.

Methods
\end{abstract}

Eight medical research databases were searched; Cochrane, Medline, Embase, UpToDate, PROSPERO, National Guideline Clearinghouse, SweMed and Oria. We followed The Preferred Reporting Items for Systematic reviews and Meta-analysis (PRISMA) for this study.

Results

Thirty-three articles were included in the systematic review, 32 of which were appropriate for the meta-analysis. Overall, $17 \%$ (95\% CI: 16-18\%) of patients in the SAVR group, and $16 \%$ (95\% CI: 15-18\%) in the TAVR groups were readmitted within 30 days. Heart failure, arrhythmia, infection, and respiratory problems were the most frequent causes of all-cause readmission after SAVR and TAVR. Most frequent reported prior risk factors for all-cause readmission following TAVR were diabetes, chronic lung disease/chronic obstructive pulmonary disease, atrial fibrillation, kidney problems, and transapical approach/nonfemoral access. For SAVR, no risk factors for 30-day all-cause readmission were reported in the literature to date.

Conclusion

In conclusion, the overall proportion of 30-day all-cause readmission after SAVR and TAVR are high. Interventions to prevent avoidable readmissions ought to be developed and implemented. 


\section{Introduction}

Today, surgical aortic valve replacement (SAVR) is the standard treatment for patients with operable severe aortic stenosis (AS) $(1,2)$. Surgical treatment for AS improves survival and enhances patients' quality of life (3-5). In older patients (>75 years) with symptomatic severe AS and who are at high surgical risk, transcatheter aortic valve replacement (TAVR) is the established alternative to SAVR $(1,6,7)$. TAVR yields favorable outcomes compared to medical treatment (8).

Arrhythmias, infections, or other complications after SAVR and TAVR are relatively frequent (9) and often require readmission to the hospital. Unplanned readmissions are costly for individuals and the public and negatively affect patients' quality of life and rehabilitation (10). Furthermore, it increases the risk for hospital-acquired complications (10). In the literature, it is reported that the incidence of 30-day all-cause readmissions after SAVR and TAVR is about one out of every four discharges results in a readmission $(9,11,12)$. However, reported readmission rates vary substantially. Hence, the precise estimation of the magnitude of the problem remains unaddressed. Moreover, risk factors for and causes of readmissions following SAVR and TAVR have not yet been systematically scrutinized. This information is important, because it can guide clinicians, hospital administrators, and policymakers in developing and implementing programs to improve the quality of care for SAVR and TAVR patients following hospital discharge. This will be even more important in the coming years, as the increasing trend in life expectancy translates to more SAVR and TAVR procedures $(5,13-15)$. An accurate estimation of readmission rates and risk factors leading up to them is also relevant for researchers in the area of valve replacement, because resulting data could be used for benchmarking and would enable researchers to calculate the sample sizes needed for future trials that assess interventions to reduce readmissions. 
These issues prompted us to conduct a systematic literature review and meta-analysis. Our aims were (i) to estimate the overall 30-day all-cause readmission rate in patients following SAVR and TAVR, and (ii) to identify risk factors for and causes of 30-day allcause readmissions after discharge of these patients.

\section{Methods}

The protocol for this systematic literature review and meta-analysis was prospectively registered in the International Prospective Register of Systematic Reviews (PROSPERO; no. 42016032670). The Preferred Reporting Items for Systematic reviews and Meta-analysis (PRISMA) guidelines were used. (16).

\section{Literature search}

The first author (SOD) developed the search strategy in collaboration with an experienced research librarian. The following databases were consulted: Cochrane (Cochrane database of Systematic Reviews, Cochrane Central Register of Controlled Trials, Cochrane Methodology Register, NHS Economic Evaluation Database, Health Technology Assessment Database and Other Reviews); Medline (accessed through PubMed; http://www.ncbi.nlm.nih.gov/pubmed); Embase; UpToDate; PROSPERO; National Guideline Clearinghouse; SveMed; and Oria.no. In addition, reference lists of candidate articles were screened to find additional references missed by our search strings (i.e., snowball method). Details on the search terms and the search strings can be found in online Table 2. Publication date limits were set from database inception to October 8, 2017. Language search was limited to English, and the Scandinavian languages. If necessary information was missing, we emailed the authors to obtain additional information. 
Articles were eligible for inclusion if they reported study results on 30-day all-cause readmission following SAVR and TAVR procedures. For the present review, we defined 30day all-cause readmission as an unplanned readmission for any reason within 30 days after discharge (17). We excluded articles that reported results from studies dealing with multiple valves or specific diseases/conditions related to the SAVR and TAVR treatment. We also excluded articles that reported results from studies dealing with procedural or cardiac-related causes or other specific causes for readmissions, because they did not address all-cause readmissions. One researcher (SOD) screened all the records identified by title, and two researchers (SOD/IL) assessed the full-text candidate articles of the first screening using the inclusion criteria listed above. Before our review was completed, we consulted the databases several more times to check whether we had missed any eligible articles (Online Table 2).

\section{Data abstraction}

Data from included articles were extracted onto a standard form according to an a priori protocol. Extracted data included information on study-related characteristics, patient-related characteristics, and main findings. The study-related variables included the article's year of publication; country where the study took place; representativeness of the cohort (singlecenter, multicenter, or nationwide data); whether the cohort was prospectively or retrospectively studied; and whether 30-day all-cause readmission was reported as a primary or secondary endpoint. Patient-related variables included mean age and proportion of the study population that were males. The results we were interested in, and what we extracted, pertained to the total sample size reported in the article and the number of events (30-day allcause readmission). 


\section{Quality of the studies}

Two researchers independently assessed the quality of the studies (SOD/IL) using the Newcastle-Ottawa Scale (NOS). NOS is an established scale for assessment of cohort studies (18). For studies with no relevant data accordingly to NOS items for appraisal, we noted them as "not relevant" (NR). Consensus by discourse resolved disagreements.

\section{Statistical analysis}

To calculate an overall incidence of 30-day all-cause readmission, we used a random effects meta-analysis of single proportions according to the DerSimonian-Laird method (19). We used the Freeman-Turkey double arcsine transformation to stabilize the variance (20). Heterogeneity between studies was assessed with the Cochran's Q test, and its magnitude was evaluated by the $\mathrm{I}^{2}$ statistic. This describes the proportion of total variation due to heterogeneity rather than chance (21). To investigate possible sources of heterogeneity, we performed analyses stratified by the study characteristic, prospective versus retrospective timing of the study, representativeness of the cohort (single- versus multi-center), country where the study took place (USA versus others), and whether or not 30-day all-cause readmission was reported as the primary endpoint. Further univariable random effects metaregression analyses were used to examine whether estimates were affected by the study-level covariates. Source of heterogeneity was considered to be important if the covariate decreased between-study variance. The estimate of $\tau 2$ in the presence of a covariate versus its omission allows the proportion of the heterogeneity variance explained by the covariate to be calculated. For power consideration, we determined that a minimum of 10 studies per covariate was required in a single model of meta-regression (22). An additional sensitivity analysis was conducted by iteratively omitting one study at a time from the meta-analysis and assessing its influence on the overall results (23). Publication bias was evaluated visually by 
funnel plots and further assessed using a test of asymmetry (Egger's test of the intercept) applied to funnel plots (24).

All statistical analyses were performed with STATA 14.0 (STATA Data Analysis and Statistical Software; StataCorp LP, College Station, TX, USA.)

\section{Results}

\section{Included articles}

One article was excluded because it reported results from another article we had already included. Another article was excluded because the mean age of participants in the study was $>80$ years. We identified a total of 6867 candidate articles (Fig.1). After duplicates were removed, we reviewed the title and abstract of 6848 articles, 6588 of which were not relevant for our purposes. The remaining 260 articles were assessed for eligibility based on full-text review; 227 were deemed ineligible. We included 33 articles in the systematic review and 32 in the meta-analysis, 12 on the SAVR population and 20 on the TAVR population.

\section{Study characteristics in included articles}

The characteristics of the studies included are presented in Online Table 1. We identified 12 cohort studies $(14,25-35)$ on SAVR, all of which were published from 2008 to 2017. Ten studies used a retrospective design, 8 studies were conducted in the USA, and 7 designated 30-day all-cause readmission as the primary endpoint. Overall, 558,396 patients were included in our review of SAVR studies, yielding 111,909 readmissions. Mean age of the included patients ranged from 61 to 81 years; the proportion of males ranged from $48 \%$ to $71 \%$. 
For articles reporting TAVR results, we identified 20 cohort studies $(6,7,11-13,28$, 34-47), which were published from 2015 to2017. Sixteen studies employed a retrospective design; 11 studies were performed in the USA; and 11 studies had 30-day all-cause readmission as a primary endpoint. In these 20 studies, 109,730 patients were included, yielding 21,192 readmissions. Mean age ranged from 80.7 to 84.3 years; the proportion of males ranged from $34 \%$ to $57 \%$.

\section{Quality assessment and publication bias}

The overall quality of studies in the included articles was moderate on the NOS. Many of these retrospective studies failed to provide descriptions of how the outcome was derived and how it was validated. Thus, this produced an overall assessment of moderate quality (online Table 3). We found no publication bias, neither in SAVR studies (Egger test, $\mathrm{p}=0.255$ ) nor in TAVR studies (Egger test, $\mathrm{p}=0.140$ ). Funnel plots are presented in online material (Online Fig. 1).

Incidence of 30-day all-cause readmission rate following SAVR or TAVR

The incidence of 30-day all-cause readmission rate for SAVR ranged from 7-23\%, and for TAVR, from 5-27\%. The pooled estimated proportion of the 30-day all-cause readmission after SAVR was 17\% (95\% CI: 16-18), with substantial heterogeneity $\left(\mathrm{I}^{2}=98.44 \%\right)$ (Fig. 2). Subgroup analysis of heterogeneity in the SAVR population revealed a significantly higher readmission rate in multicenter studies (20\%) compared to single-center studies (12\%) (Table 1). Regional differences were also observed, with higher readmission rates in the USA (18\%) compared to other countries (14\%). A lower incidence of readmissions was found in prospective (14\%) compared to retrospective (17\%) studies. We also found a difference in 
studies reporting on readmission as a primary $(17 \%)$ versus secondary $(15 \%)$ endpoint (Table 1).

The pooled estimated proportion of the 30-day all-cause readmission after TAVR was 16\% (95\% CI: $15-18)$, also with substantial heterogeneity $\left(I^{2}=97.06 \%\right)$ (Fig. 2). Subgroup analysis revealed more readmissions in multicenter studies $(18 \%)$ compared to single-center studies (12\%) (Table 1). Regional differences were observed, with a higher incidence in the USA $(18 \%)$ compared to other countries (14\%). A lower incidence was found in prospective (11\%) studies compared to retrospective (17\%) studies.

We also extended the analyses by using a random effect meta-regression model in the univariable mode. With this approach, we found that the only study-level variable significantly associated with readmission rate was single-center studies versus multicenter studies (Table 2). Sixty-nine percent of between-study heterogeneity was accounted for by this study-level variable in the SAVR population ( $\mathrm{p}=0.013)$, and $24 \%$ in the TAVR population $(\mathrm{p}=0.038)$. Furthermore, USA versus other countries was marginally associated with readmission in the TAVR population $(\mathrm{p}=0.091)$.

In the meta-analysis, the results from the sensitivity analyses appeared to be robust against the influence of individual studies.

\section{Cause of 30-day all-cause readmissions after SAVR and TAVR}

We found three articles reporting on causes of 30-day all-cause readmissions for SAVR patients $(28,31,34)$. Heart failure (15-19\%) and cardiac rhythm disorder (10-14\%) were the most frequently reported causes of 30-day all-cause readmission after SAVR. Infections, lung complications/respiratory problems, and bleedings ranged from 3-14\%, as causes of readmissions after SAVR (Online Table 4). 
We found nine articles reporting on causes of 30-day all-cause readmissions after TAVR. Heart failure (up to $30 \%$ ), respiratory problems (up to 14\%), infections (up to 13\%), and arrhythmia (up to 10\%) were the most frequently reported causes of 30-day all-cause readmission after TAVR (Online Table 5).

Risk factors for 30-day all-cause readmissions after SAVR and TAVR

We identified six articles reporting data on risk factors for 30-day all-cause readmission after TAVR $(7,11,37,39,40,48)$. Independent risk factors of diabetes (OR: 1.13-1.18); chronic lung disease/chronic obstructive pulmonary disease (COPD) (OR: 1.181.32, HR: 1.16); atrial fibrillation (OR: 1.26-1.70); kidney-related access (OR: 1.33-1.62, HR: 1.20-1.23); and transapical approach/nonfemoral access (OR: 1.21-1.43) were among the most frequently reported risk factors. Risk factors with an OR value of $>2.0$ were major/life threatening bleeding (2.41), length of stay of 7-10 days during primary admission (2.32), length of stay of $>10$ days during primary admission (3.06), and second prior admission in the year before TAVR (2.33). Details are included in online Table 6.

We found no articles that comprehensively reported on risk factors for 30-day allcause readmission after SAVR.

\section{Discussion}

Reported hospital readmission rates vary substantially following SAVR and TAVR, obscuring rational guidance for clinicians, hospital administrators, and policy-makers. An accurate estimation of readmission rates and risk factors is also relevant for researchers, because reliable estimates are needed for benchmarking new valve replacement prototypes and to calculate study population sample sizes. 
The meta-analysis we report here estimated a pooled 30-day all-cause readmission rate of $17 \%$ for SAVR and $16 \%$ for TAVR. The readmission rates are high, which we know are an additional burden for patients and caregivers, costly for society, and increase the risk of hospital-acquired infections and other errors (10). Poor quality of care and transitional care contributes to high numbers of readmissions, but some readmissions are not necessarily attributable to the quality of care (49). Some are unavoidable and occur due to expected complications after the treatments (49). We don't know the proportion of avoidable readmissions after SAVR and TAVR, and this makes the interpretation of readmissions as a quality indicator difficult. Greater age and higher comorbidity, and major surgery, suggest a need to examine the proportions of avoidable and unavoidable readmissions after SAVR and TAVR. Having firm data on avoidable and unavoidable readmissions would help healthcare professionals to tailor new interventions to prevent readmissions, especially avoidable ones, and to improve transitional care in order to reduce burdens associated with readmissions.

Studies on 30-day all-cause readmission rates in SAVR and TAVR populations, support the notion that the proportion of readmissions in these two groups of patients are not significantly different $(28,34)$, and are approximately similar to the estimates of the metaanalysis. However, because the populations differ (e.g., in age and comorbidity), one cannot obtain generalizable data by directly comparing the 30-day all-cause readmission rates between SAVR and TAVR patients (28). When the two groups of patients were matched, though, the 30-day all-cause readmission rates seem to be similar (28). Interestingly, studies have shown that TAVR done with a transapical approach (TAVR-TA) seems to produce a higher proportion of readmissions than TAVR done with a transfemoral approach (TAVRTF) and SAVR (43), possibly due to a higher risk profile (34).

In the SAVR and TAVR studies we analyzed, we found a significant increase in the proportion of 30-day all-cause readmissions in multicenter studies compared to single-center 
studies. Cohort studies with 30-day all-cause readmission numbers retrieved from large administrative databases might capture more readmissions than single-center studies. Singlecenter studies might not capture all readmissions if patients are admitted to other hospitals outside their area (33). Moreover, registry data can also be biased/corrupt (50). Indeed, studies depending on administrative data from a registry rarely contain detailed descriptions of how the data were validated (50). When evaluating the methodological quality of the included studies, we found that none of them provided a detailed transparent statement on the validity of the 30-day all-cause readmission numbers.

We observed regional differences among studies in the meta-analysis, with more 30day all-cause readmissions in the USA versus other countries. In October 2012, the USA began to penalize hospitals (Medicare) as part of the Hospital Readmission Reduction Program (HRRP) under the Patient Protection and Affordable Care Act. HRRP has led to increased interest and research into the field of readmissions in the USA, and this might explain a difference between the USA and other countries. Even though readmissions have declined since 2012 for certain diagnoses for Medicare fee-for-service patients (51), more readmissions after 30 days and 1 year are reported for the USA compared to other countries in, for example, the TAVR population (52).

Causes of 30-day all-cause readmissions after SAVR are poorly described. In this systematic review, we found that heart failure and heart rhythm disturbances are prominent causes. This is similar to the reported causes for readmissions after cardiac surgery, in general, in addition to infections and bleeding (53). In the TAVR population, heart failure is the most frequently reported cause of 30-day all-cause readmission. However, heart blocks are also common (35), requiring postoperative implantations of permanent pacemakers in 10$30 \%$ of the patients $(54,55)$. 
Examining the risk factors for 30-day all-cause readmission after TAVR showed that these patients harbor high comorbidity and an underlying frailty $(11,34)$. COPD, diabetes, heart failure, greater age, and being female have been reported to be predictors for 30-day allcause readmission after cardiac surgery $(9,33,53,56-59)$. Many of these predictors for readmissions are also described in the general cardiac surgery population. Risk factors for 30day all-cause readmission after SAVR are not comprehensively described, at least for articles included in our exhaustive search.

\section{Clinical implications}

Recent evidence suggests a slight increase in mortality among heart-failure patients, simultaneously with the reduction of readmissions due to the implementation of HRRP in the USA (60). Knowing that heart failure is a prominent cause and risk factor of readmissions after invasive cardiac procedures, such as SAVR and TAVR, this gives rise to concern for the care of these populations in the discharge and early rehabilitation phase.

Given that the population of older ones continues to increase, we expect that SAVR and TAVRs procedures also will increase in the coming years. If most readmissions after SAVR and TAVR are unavoidable, then we should tolerate a higher number of readmissions to avoid unintended consequences of focusing exclusively on avoiding readmissions. One meta-analysis showed that $27 \%$ of readmissions are considered to have been avoidable (61). Increasing the quality of symptom monitoring in the early phase after discharge might prevent avoidable readmissions and maintain patient safety for those who must be readmitted (62). 


\section{Research implications}

The overall numbers of 30-day all-cause readmissions after SAVR and TAVR can be used to achieve more robustly powered studies. Indeed, the present meta-analysis provides reliable figures for calculating sample sizes for future intervention studies (e.g., aiming to reduce readmissions) (63) or for improving the transition of care. Furthermore, the high number of readmissions underscores a greater need for research aimed at determining the proportion of avoidable readmissions, because that type of readmission is auspicious for quality-enhancing interventions. Completing more prospective studies will ensure higher data quality and detailed follow-up. Finally, to understand and to be able to appraise the readmission statistics, transparency on how the readmission numbers are validated in research should be comprehensively reported in the publications.

\section{Methodological considerations}

The present systematic review and meta-analysis has methodological strengths. In both the SAVR and TAVR groups, there were more than 10 appropriate articles evaluated, which enabled us to perform a random effects meta-regression on study-level variables. Furthermore, none of the included articles reported on studies that were of poor quality. The extensive search we conducted implies that we likely missed few or no relevant studies. In addition, we found no publication bias, and the sensitivity analysis shows that the results are robust and strengthens validity of the results from the meta-analysis.

However, there were also some methodological limitations of our review and analysis that warrant discussion. First, there was great heterogeneity between the studies reported on which could be caused by differences in competence among surgeons, cardiologists, intervention radiologists, etc. There were also differences in patient volumes among the hospitals, device usage, and follow-up strategies after discharge. This heterogeneity limits to 
some degree what can be interpreted from the results. Second, the reporting of clinical data was inconsistent. This inconsistency prevented us from doing a random meta-regression analysis on patient-level variables. Third, none of the included articles provided a detailed, transparent validation of the readmission data presented in the articles. In large retrospective trials, administrative databases are often used to obtain the readmissions figures. It is well known that, with these databases, there are errors in coding practice and methodological problems regarding extraction of exact, relevant data $(50,64)$. Fourth, English-language bias can have been introduced due to our language limitations, but likely with less effect (65). Fifth, the proportions of avoidable and unavoidable readmissions are not described, making it difficult to evaluate to what degree the readmissions after SAVR and TAVR are a matter of quality of care or an anticipated clinical outcome due to the natural course of the condition after treatment. Because of this issue, some believe that readmission is not a reliable quality measurement of hospital care for cardiac surgery patients (66).

\section{Conclusions}

Our findings demonstrate a high proportion of 30-day all-cause readmissions after SAVR (17\%) and TAVR (16\%). In the SAVR group, higher readmission rates were reported in multicenter studies, the USA, retrospective studies, and studies with readmission as the primary outcome. In the TAVR group, higher readmission rates were reported in multicenter studies, the USA, and in retrospective studies. Heart failure and hearth rhythm disturbances are common causes of readmission in patients with heart valve problems. The results of the present systematic review and meta-analysis provide new impetus for conducting quality-

enhancing projects and provide the necessary data for accurately calculating sample sizes for future trials. 
Acknowledgements: We thank Marie Susanna Isachsen, Senior Librarian, Medical Library, University of Oslo Library. 
Reference List

1. Falk V, Baumgartner H, Bax JJ, De Bonis M, Hamm C, Holm PJ, et al. 2017 ESC/EACTS Guidelines for the management of valvular heart disease. European journal of cardio-thoracic surgery : official journal of the European Association for Cardio-thoracic Surgery. 2017;52(4):616-64. 2. Otto CM, Baumgartner H. Updated 2017 European and American guidelines for prosthesis type and implantation mode in severe aortic stenosis. Heart (British Cardiac Society). 2017.

3. Chiang YP, Chikwe J, Moskowitz AJ, Itagaki S, Adams DH, Egorova NN. Survival and long-term outcomes following bioprosthetic vs mechanical aortic valve replacement in patients aged 50 to 69 years. Jama. 2014;312(13):1323-9.

4. Shan L, Saxena A, McMahon R, Wilson A, Newcomb A. A systematic review on the quality of life benefits after aortic valve replacement in the elderly. The Journal of thoracic and cardiovascular surgery. 2013;145(5):1173-89.

5. Siregar S, de Heer F, Groenwold RH, Versteegh MI, Bekkers JA, Brinkman ES, et al. Trends and outcomes of valve surgery: 16-year results of Netherlands Cardiac Surgery National Database. European journal of cardio-thoracic surgery : official journal of the European Association for Cardiothoracic Surgery. 2014;46(3):386-97; discussion 97.

6. Holmes DR, Jr., Mack MJ, Kaul S, Agnihotri A, Alexander KP, Bailey SR, et al. 2012

ACCF/AATS/SCAI/STS expert consensus document on transcatheter aortic valve replacement: developed in collaboration with the American Heart Association, American Society of Echocardiography, European Association for Cardio-Thoracic Surgery, Heart Failure Society of America, Mended Hearts, Society of Cardiovascular Anesthesiologists, Society of Cardiovascular Computed Tomography, and Society for Cardiovascular Magnetic Resonance. The Annals of thoracic surgery. 2012;93(4):1340-95.

7. Nombela-Franco L, del Trigo M, Morrison-Polo G, Veiga G, Jimenez-Quevedo $P$, Abdul-Jawad Altisent $\mathrm{O}$, et al. Incidence, Causes, and Predictors of Early ( $</=30$ Days) and Late Unplanned Hospital Readmissions After Transcatheter Aortic Valve Replacement. JACC Cardiovascular interventions. 2015;8(13):1748-57.

8. Leon MB, Smith CR, Mack MJ, Makkar RR, Svensson LG, Kodali SK, et al. Transcatheter or Surgical Aortic-Valve Replacement in Intermediate-Risk Patients. The New England journal of medicine. 2016.

9. Sibilitz KL, Berg SK, Thygesen LC, Hansen TB, Kober L, Hassager C, et al. High readmission rate after heart valve surgery: A nationwide cohort study. International journal of cardiology.

2015;189:96-104.

10. Horwitz L, Partovian, C., Lin, Z., Herrin, J., Grady, J., Conover, M., Montague, J., Dillaway, C., Bartczak, K., Ross, J., Bernheim, S., Drye, E., Krumholz, HM. Hospital-Wide (All-Condition) 30-Day Risk-Standardized Readmission Measure DRAFT Measure Methodology Report. Yale New Haven Health Services Corporation/Center for Outcomes Research \& Evaluation (YNHHSC/CORE); 2011 August 10, 2011.

11. Panaich SS, Arora S, Patel N, Lahewala S, Agrawal Y, Patel NJ, et al. Etiologies and Predictors of 30-Day Readmission and In-Hospital Mortality During Primary and Readmission After Transcatheter Aortic Valve Implantation. The American journal of cardiology. 2016;118(11):1705-11. 12. Wu SS, Wang TK, Nand P, Ramanathan T, Webster M, Stewart J. Early outcome of patients undergoing transcatheter aortic valve implantation (TAVI): The Auckland City Hospital experience 2011-2015. The New Zealand medical journal. 2016;129(1428):47-55.

13. Ailawadi G, LaPar DJ, Speir AM, Ghanta RK, Yarboro LT, Crosby IK, et al. Contemporary Costs Associated With Transcatheter Aortic Valve Replacement: A Propensity-Matched Cost Analysis. The Annals of thoracic surgery. 2016;101(1):154-60; discussion 60.

14. Barreto-Filho JA, Wang Y, Dodson JA, Desai MM, Sugeng L, Geirsson A, et al. Trends in aortic valve replacement for elderly patients in the United States, 1999-2011. Jama. 2013;310(19):2078-85. 
15. Lee R, Li S, Rankin JS, O'Brien SM, Gammie JS, Peterson ED, et al. Fifteen-year outcome trends for valve surgery in North America. The Annals of thoracic surgery. 2011;91(3):677-84; discussion $p 84$.

16. Moher D, Liberati A, Tetzlaff J, Altman DG. Preferred reporting items for systematic reviews and meta-analyses: the PRISMA statement. Journal of clinical epidemiology. 2009;62(10):1006-12.

17. Medicare.gov. 30-day unplannned readmission and death measures. Accessed November 10, 2017. USA: Medicare; 2017 [Available from: https://www.medicare.gov/hospitalcompare/Data/30day-measures.html.

18. GA Wells BS, D O'Connell, J Peterson, V Welch, M Losos, P Tugwell. The Newcastle-Ottawa Scale (NOS) for assessing the quality of nonrandomised studies in meta-analyses. Accessed Novemer 10, 2017.: Ottawa Hospital Research Institute; 2014 [Available from:

http://www.ohri.ca/programs/clinical epidemiology/oxford.asp.

19. DerSimonian R, Laird N. Meta-analysis in clinical trials. Controlled clinical trials. 1986;7(3):177-88.

20. Freeman $M$, Turkey, JW. Transformation related to the angular and the square roots. Annals of mathematical statistics. 1950;21:607-11.

21. Higgins JP, Thompson SG, Deeks JJ, Altman DG. Measuring inconsistency in meta-analyses. BMJ (Clinical research ed). 2003;327(7414):557-60.

22. Peduzzi P, Concato J, Kemper E, Holford TR, Feinstein AR. A simulation study of the number of events per variable in logistic regression analysis. Journal of clinical epidemiology. 1996;49(12):1373-9.

23. Viechtbauer $\mathrm{W}$, Cheung MW. Outlier and influence diagnostics for meta-analysis. Research synthesis methods. 2010;1(2):112-25.

24. Egger M, Davey Smith G, Schneider M, Minder C. Bias in meta-analysis detected by a simple, graphical test. BMJ : British Medical Journal. 1997;315(7109):629-34.

25. Arora S, Panaich S, Patel V, Patel N, Bambhroliya C, Dhaduk K, et al. Abstract 13933: A Comparative Analysis of 30-day Readmission Rates, Etiologies and Resource Utilization Following Transcatheter and Surgical Aortic Valve Replacement From the Nationwide Readmission Database. Circulation. 2016;134(Suppl_1 Suppl 1):A13933-A.

26. Auensen A, Hussain Al, Bendz B, Aaberge L, Falk RS, Walle-Hansen MM, et al. Morbidity outcomes after surgical aortic valve replacement. Open heart. 2017;4(1):e000588.

27. Brown ML, Schaff HV, Lahr BD, Mullany CJ, Sundt TM, Dearani JA, et al. Aortic valve replacement in patients aged 50 to 70 years: Improved outcome with mechanical versus biologic prostheses. The Journal of thoracic and cardiovascular surgery. 2008;135(4):878-84.

28. Hannan EL, Samadashvili Z, Jordan D, Sundt TM, 3rd, Stamato NJ, Lahey SJ, et al. Thirty-Day Readmissions After Transcatheter Aortic Valve Implantation Versus Surgical Aortic Valve Replacement in Patients With Severe Aortic Stenosis in New York State. Circulation Cardiovascular interventions. 2015;8(8):e002744.

29. Kuo K, Shah P, Hiebert B, Love K, Menkis AH, Manji RA, et al. Predictors of survival, functional survival, and hospital readmission in octogenarians after surgical aortic valve replacement. The Journal of thoracic and cardiovascular surgery. 2017.

30. Lancaster E, Postel M, Satou N, Shemin R, Benharash P. Introspection into institutional database allows for focused quality improvement plan in cardiac surgery: example for a new global healthcare system. The American surgeon. 2013;79(10):1040-4.

31. McNeely C, Telila T, Markwell S, Hazelrigg S, Vassileva CM. Hospital Readmission after Aortic Valve Replacement: Impact of Preoperative Heart Failure. The Journal of heart valve disease. 2016;25(4):430-6.

32. Murugiah K, Wang Y, Dodson JA, Nuti SV, Dharmarajan K, Ranasinghe I, et al. Trends in hospitalizations among medicare survivors of aortic valve replacement in the United States from 1999 to 2010. The Annals of thoracic surgery. 2015;99(2):509-17. 
33. Redzek A, Mironicki M, Gvozdenovic A, Petrovic M, Cemerlic-Adic N, llic A, et al. Predictors for hospital readmission after cardiac surgery. Journal of cardiac surgery. 2015;30(1):1-6.

34. Vejpongsa P, Bhise V, Charitakis K, Vernon Anderson H, Balan P, Nguyen TC, et al. Early readmissions after transcatheter and surgical aortic valve replacement. Catheterization and cardiovascular interventions : official journal of the Society for Cardiac Angiography \& Interventions. 2017.

35. Zweng I, Shi WY, Palmer S, Maclsaac A, Whitbourn R, Davis P, et al. Transcatheter versus Surgical Aortic Valve Replacement in High-risk Patients: A propensity-score matched analysis. Heart, lung \& circulation. 2016.

36. Czarnecki A, Qiu F, Koh M, Prasad TJ, Cantor WJ, Cheema AN, et al. Clinical outcomes after trans-catheter aortic valve replacement in men and women in Ontario, Canada. Catheterization and cardiovascular interventions : official journal of the Society for Cardiac Angiography \& Interventions. 2017;90(3):486-94.

37. Dodson JA, Williams MR, Cohen DJ, Manandhar P, Vemulapalli S, Blaum C, et al. Hospital Practice of Direct-Home Discharge and 30-Day Readmission After Transcatheter Aortic Valve Replacement in the Society of Thoracic Surgeons/American College of Cardiology Transcatheter Valve Therapy (STS/ACC TVT) Registry. Journal of the American Heart Association. 2017;6(8).

38. Eide LS, Ranhoff AH, Fridlund B, Haaverstad R, Hufthammer KO, Kuiper KK, et al. Readmissions and mortality in delirious versus non-delirious octogenarian patients after aortic valve therapy: a prospective cohort study. BMJ Open. 2016;6(10):e012683.

39. Forcillo J, Condado JF, Binongo JN, Lasanajak Y, Caughron H, Babaliaros V, et al. Readmission rates after transcatheter aortic valve replacement in high- and extreme-risk patients with severe aortic stenosis. The Journal of thoracic and cardiovascular surgery. 2017;154(2):445-52.

40. Harvey J, Clancy S, Rutkin B. Predictors of Hospital Readmissions After Transcatheter Aortic Valve Replacement. J Am Coll Cardiol. 2016;68(18):B13-B4.

41. Khera S, Kolte D, Gupta T, Goldsweig A, Velagapudi P, Kalra A, et al. Association Between Hospital Volume and 30-Day Readmissions Following Transcatheter Aortic Valve Replacement. JAMA Cardiol. 2017;2(7):732-41.

42. Lauck SB, Wood DA, Baumbusch J, Kwon JY, Stub D, Achtem L, et al. Vancouver Transcatheter Aortic Valve Replacement Clinical Pathway: Minimalist Approach, Standardized Care, and Discharge Criteria to Reduce Length of Stay. Circulation Cardiovascular quality and outcomes. 2016;9(3):312-21.

43. McNeely C, Zajarias A, Robbs R, Markwell S, Vassileva CM. Transcatheter Aortic Valve Replacement Outcomes in Nonagenarians Stratified by Transfemoral and Transapical Approach. The Annals of thoracic surgery. 2017;103(6):1808-14.

44. Murugiah K, Wang Y, Desai NR, Nuti SV, Krumholz HM. Hospital Variation in Outcomes for Transcatheter Aortic Valve Replacement Among Medicare Beneficiaries, 2011 to 2013. Journal of the American College of Cardiology. 2015;66(23):2678-9.

45. Noad RL, Johnston N, McKinley A, Dougherty M, Nzewi OC, Jeganathan R, et al. A pathway to earlier discharge following TAVI: Assessment of safety and resource utilization. Catheterization and cardiovascular interventions : official journal of the Society for Cardiac Angiography \& Interventions. 2015.

46. Sawa Y, Takayama M, Mitsudo K, Nanto S, Takanashi S, Komiya T, et al. Clinical efficacy of transcatheter aortic valve replacement for severe aortic stenosis in high-risk patients: the PREVAIL JAPAN trial. Surgery today. 2015;45(1):34-43.

47. Sud M, Qui F, Austin PC, Ko DT, Wood D, Czarnecki A, et al. Short Length of Stay After Elective Transfemoral Transcatheter Aortic Valve Replacement is Not Associated With Increased Early or Late Readmission Risk. Journal of the American Heart Association. 2017;6(4).

48. Kolte D, Khera S, Sardar MR, Gheewala N, Gupta T, Chatterjee S, et al. Thirty-Day Readmissions After Transcatheter Aortic Valve Replacement in the United States: Insights From the Nationwide Readmissions Database. Circulation Cardiovascular interventions. 2017;10(1). 
49. Fischer C, Lingsma HF, Marang-van de Mheen PJ, Kringos DS, Klazinga NS, Steyerberg EW. Is the Readmission Rate a Valid Quality Indicator? A Review of the Evidence. PloS one.

2014;9(11):e112282.

50. van Walraven $C$, Austin P. Administrative database research has unique characteristics that can risk biased results. Journal of clinical epidemiology. 2012;65(2):126-31.

51. Desai NR, Ross JS, Kwon JY, Herrin J, Dharmarajan K, Bernheim SM, et al. Association Between Hospital Penalty Status Under the Hospital Readmission Reduction Program and Readmission Rates for Target and Nontarget Conditions. Jama. 2016;316(24):2647-56.

52. Sukul D, Bach DS. Readmissions after transcatheter aortic valve implantation. What are they doing right? How can we do better? European heart journal. 2017;38(28):2218-20.

53. Iribarne A, Chang H, Alexander JH, Gillinov AM, Moquete E, Puskas JD, et al. Readmissions after cardiac surgery: experience of the National Institutes of Health/Canadian Institutes of Health research cardiothoracic surgical trials network. The Annals of thoracic surgery. 2014;98(4):1274-80. 54. Khan MH, Ahmad, H.A. AV Block and PPM Implantation in TAVR American College of Cardiology: ACC.org; 2017 [updated June 13, 2017.

55. Young Lee M, Chilakamarri Yeshwant S, Chava S, Lawrence Lustgarten D. Mechanisms of Heart Block after Transcatheter Aortic Valve Replacement - Cardiac Anatomy, Clinical Predictors and Mechanical Factors that Contribute to Permanent Pacemaker Implantation. Arrhythmia \& electrophysiology review. 2015;4(2):81-5.

56. D'Agostino RS, Jacobson J, Clarkson M, Svensson LG, Williamson C, Shahian DM. Readmission after cardiac operations: Prevalence, patterns, and predisposing factors. The Journal of thoracic and cardiovascular surgery. 1999;118(5):823-32.

57. Ferraris VA, Ferraris SP, Harmon RC, Evans BD. Risk factors for early hospital readmission after cardiac operations. The Journal of thoracic and cardiovascular surgery. 2001;122(2):278-86. 58. Lee R, Homer N, Andrei AC, McGee EC, Malaisrie SC, Kansal P, et al. Early readmission for congestive heart failure predicts late mortality after cardiac surgery. The Journal of thoracic and cardiovascular surgery. 2012;144(3):671-6.

59. Maniar HS, Bell JM, Moon MR, Meyers BF, Marsala J, Lawton JS, et al. Prospective evaluation of patients readmitted after cardiac surgery: analysis of outcomes and identification of risk factors. The Journal of thoracic and cardiovascular surgery. 2014;147(3):1013-8.

60. Fonarow GC, Konstam MA, Yancy CW. The Hospital Readmission Reduction Program Is Associated With Fewer Readmissions, More Deaths. Time to Reconsider. 2017;70(15):1931-4.

61. van Walraven C, Jennings A, Forster AJ. A meta-analysis of hospital 30-day avoidable readmission rates. Journal of evaluation in clinical practice. 2012;18(6):1211-8.

62. Burke R, Guo R, Prochazka A, Misky G. Identifying keys to success in reducing readmissions using the ideal transitions in care framework. BMC Health Services Research. 2014;14:423.

63. Lie I, Danielsen SO, Tonnessen T, Solheim S, Leegaard M, Sandvik L, et al. Determining the impact of 24/7 phone support on hospital readmissions after aortic valve replacement surgery (the AVRre study): study protocol for a randomised controlled trial. Trials. 2017;18(1):246.

64. Sellers MM, Merkow RP, Halverson A, Hinami K, Kelz RR, Bentrem DJ, et al. Validation of new readmission data in the American College of Surgeons National Surgical Quality Improvement Program. Journal of the American College of Surgeons. 2013;216(3):420-7.

65. Morrison A, Polisena J, Husereau D, Moulton K, Clark M, Fiander M, et al. The effect of English-language restriction on systematic review-based meta-analyses: a systematic review of empirical studies. International journal of technology assessment in health care. 2012;28(2):138-44. 66. Shih T, Dimick JB. Reliability of readmission rates as a hospital quality measure in cardiac surgery. The Annals of thoracic surgery. 2014;97(4):1214-8. 
Figure 1, heading: Figure 1. PRISMA flowchart describing literature search and article selection.

Figure 2, heading: Figure 2. Forest plots summarizing the proportions of 30-day all-cause readmission after surgical and transcatheter aortic valve replacement (SAVR and TAVR). 

Table 1 Pooled estimate of total incidence of readmission with stratification on study-level characteristics using the random effect model.

\begin{tabular}{|c|c|c|c|c|c|c|}
\hline & SAVR* & & & TA & & \\
\hline Subdivision & $\mathbf{N}$ & Incidence (95\% CI) & $\mathbf{I}^{2}(\%)$ & $\mathbf{N}$ & Incidence (95\% CI) & $I^{2}(\%)$ \\
\hline All studies & 12 & $0.17(0.16-0.18)$ & 98.44 & 20 & $0.16(0.15-0.18)$ & 97.06 \\
\hline Single center & 6 & $0.12(0.08-0.17)$ & 93.31 & 6 & $0.12(0.08-0.13)$ & 80.00 \\
\hline Multi center & 6 & $0.20(0.18-0.21)$ & 98.95 & 14 & $0.18(0.16-0.19)$ & 97.64 \\
\hline \multicolumn{7}{|l|}{ Country } \\
\hline USA & 8 & $0.18(0.17-0.19)$ & 98.75 & 11 & $0.18(0.16-0.20)$ & 98.21 \\
\hline Other & 4 & $0.14(0.09-0.20)$ & 94.53 & 9 & $0.14(0.11-0.17)$ & 79.80 \\
\hline \multicolumn{7}{|c|}{ Primary endpoint } \\
\hline Yes & 7 & $0.17(0.16-0.19)$ & 98.43 & 11 & $0.17(0.16-0.19)$ & 96.82 \\
\hline No & 5 & $0.15(0.10-0.20)$ & 97.14 & 9 & $0.15(0.12-0.18)$ & 97.11 \\
\hline \multicolumn{7}{|c|}{ Timing of study } \\
\hline Prospective & 2 & $0.14(0.12-0.17)$ & 99.80 & 4 & $0.11(0.06-0.18)$ & 97.53 \\
\hline Retrospective & 10 & $0.17(0.16-0.18)$ & 98.59 & 16 & $0.17(0.16-0.19)$ & 79.69 \\
\hline
\end{tabular}

*SAVR= surgical aortic valve replacement, ${ }^{\dagger} \mathrm{TAVR}=$ transcatheter aortic valve replacement 

Table 2 Estimate of the random effect meta-regression model between incidence of readmission and the study-level variables.

\begin{tabular}{lllllllll}
\hline Covariates & N & Level & $\boldsymbol{\beta}$-coefficient & Std. Error $(\boldsymbol{\beta})$ & $\mathbf{t}$ & p-value & $\boldsymbol{\tau}^{\mathbf{2}}$ & $\begin{array}{c}\boldsymbol{* A A d j}^{\mathbf{2}} \\
(\boldsymbol{\%})\end{array}$ \\
\hline SAVR $^{\dagger}$ & & & & & & & & \\
\hline None & & & & & & & & \\
Single center & 12 & - & 0.1723 & 0.0149 & 11.54 & $<0.001$ & 0.00157 & - \\
Prospective & 12 & Yes/no & -0.0698 & 0.0231 & -3.01 & 0.013 & 0.0004 & 69.20 \\
Primary endpoint & 12 & Yes/no & -0.0129 & 0.0523 & -0.25 & 0.810 & 0.0016 & -8.48 \\
USA & 12 & Yes/no & 0.0270 & 0.0311 & 0.87 & 0.406 & 0.0014 & 1.16 \\
\hline TAVR & 12 & Yes/no & 0.0488 & 0.0321 & 4.82 & 0.160 & 0.0008 & 46.48 \\
\hline None & & & & & & & & \\
Single center & 20 & - & 0.1793 & 0.0093 & 19.18 & $<0.001$ & 0.0008 & - \\
Prospective & 20 & Yes/no & -0.0529 & 0.0315 & -2.24 & 0.038 & 0.0006 & 23.78 \\
Primary endpoint & 20 & Yes/no & 0.0209 & 0.0393 & -1.35 & 0.195 & 0.0008 & 5.53 \\
USA & 20 & Yes/no & -0.0014 & 0.0209 & -0.07 & 0.946 & 0.0009 & -10.71 \\
\hline
\end{tabular}

*Heterogeneity accounted by the covariate, ${ }^{\dagger} \mathrm{SAVR}=$ surgical aortic valve replacement, ${ }^{*} \mathrm{TAVR}=$ transcatheter aortic

valve replacement 

Figure 1. PRISMA flowchart describing literature search and article selection.

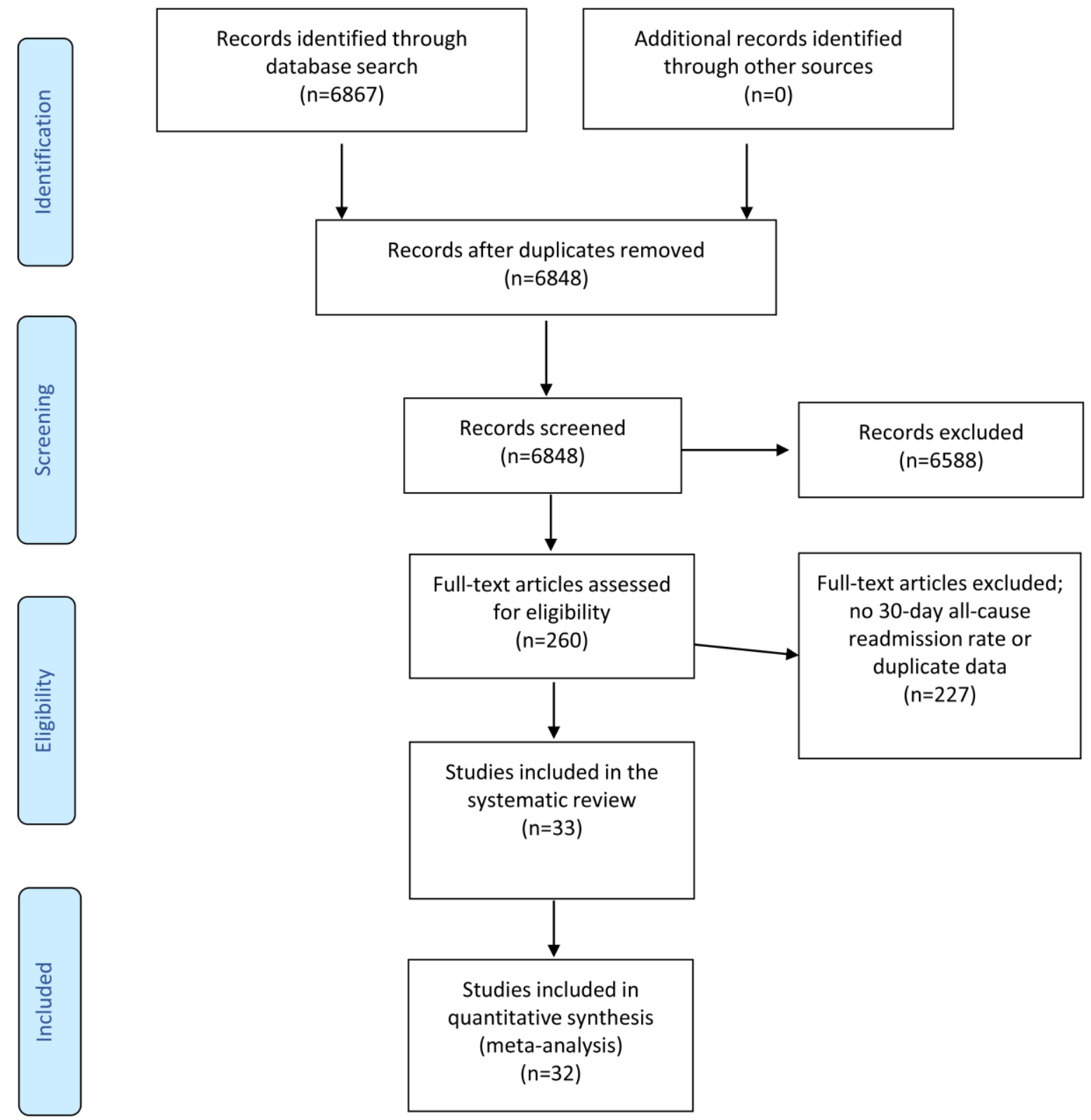


Figure 2. Forest plots summarizing the proportions of 30-day all-cause readmission after surgical and transcatheter aortic valve replacement (SAVR and TAVR).

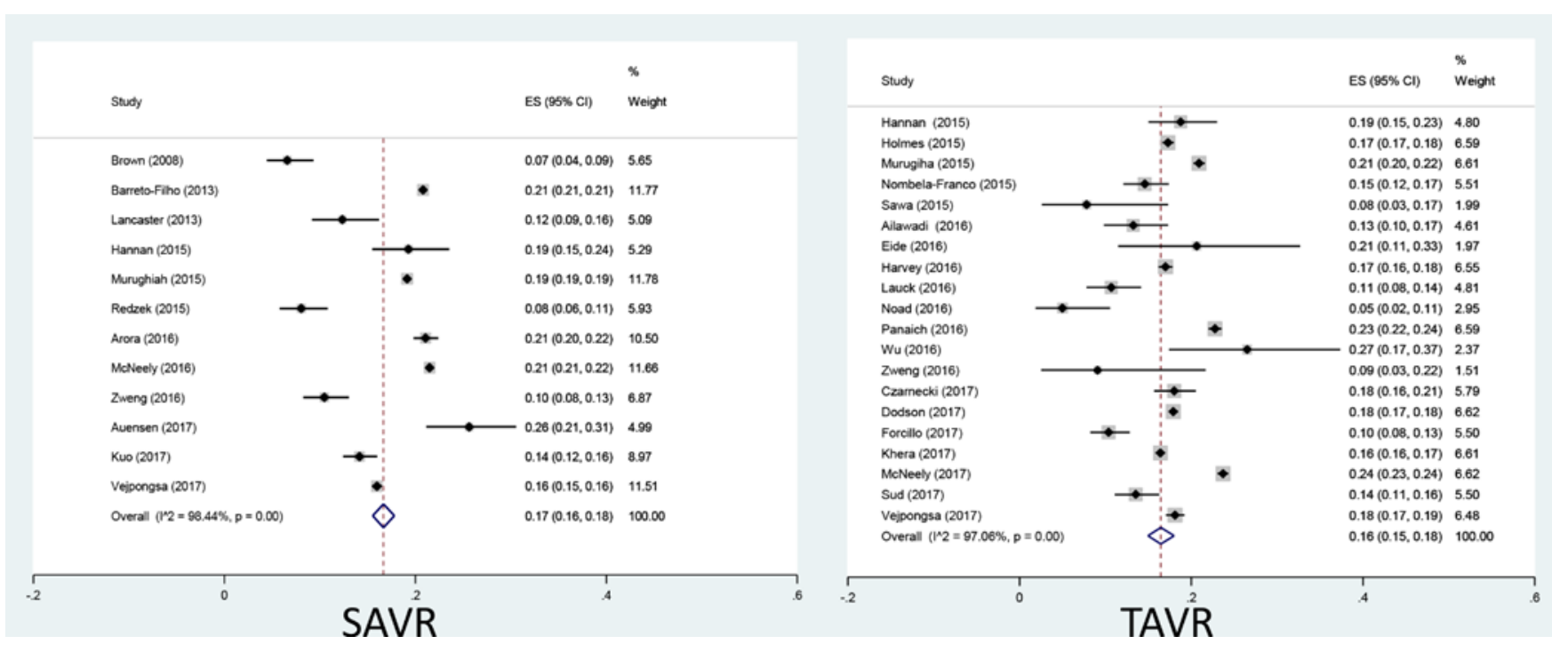


Online Table 1. Study- and patient-level characteristics of 32 articles included in the meta-analysis stratified by surgical aortic valve replacement (SAVR) and transcatheter aortic valve replacement (TAVR).

\begin{tabular}{|c|c|c|c|c|c|c|c|c|c|c|}
\hline $\begin{array}{l}\text { First author } \\
\text { of article }\end{array}$ & $\begin{array}{l}\text { Publication } \\
\text { year }\end{array}$ & Country & Data source & $\begin{array}{l}\text { Year of } \\
\text { study }\end{array}$ & $\begin{array}{l}\text { Primary } \\
\text { endpoint* }\end{array}$ & $\begin{array}{l}\text { Prospective } \\
\text { cohort study }\end{array}$ & $\begin{array}{l}\text { Mean } \\
\text { age }\end{array}$ & $\begin{array}{l}\text { Male } \\
(\%)\end{array}$ & $\begin{array}{l}\text { Sample } \\
\text { size }\end{array}$ & $\begin{array}{l}\text { Readmission } \\
\text { s n }(\%)\end{array}$ \\
\hline \multicolumn{11}{|l|}{ SAVR } \\
\hline Brown & 2008 & USA & Single center & $1991-2000$ & No & No & 66.2 & 70.5 & 440 & $29(7)$ \\
\hline Lancaster & 2013 & USA & Single center & 2008-2011 & Yes & No & 60.5 & 64.5 & 364 & $45(12)$ \\
\hline Barreto-Filho & 2013 & USA & Multicenter & 1999-2011 & Yes & No & 76.6 & 58.4 & 197,876 & $41,179(21)$ \\
\hline Hannan & 2015 & USA & Multicenter & 2011-2012 & Yes & No & 81.2 & 48.0 & 389 & 75 (19) \\
\hline Murughiah & 2015 & USA & Multicenter & 1999-2010 & No & No & 76.4 & 59.0 & 293,853 & $56,229(19)$ \\
\hline Redzek & 2015 & Serbia & Single center & 2012 & Yes & Yes & 65.3 & 68.0 & 484 & $39(8)$ \\
\hline Arora & 2016 & USA & Multicenter & 2013 & Yes & No & 79.5 & 54.0 & 3,886 & $819(21)$ \\
\hline Zweng & 2016 & Australia & Single center & $2008-2015$ & No & No & 71.0 & 68.0 & 669 & $70(10)$ \\
\hline McNeely & 2016 & USA & Multicenter & 2011-2013 & Yes & No & $76^{\dagger}$ & NR & 40,751 & $8,761(21)$ \\
\hline Vejpongsa & 2017 & USA & Multicenter & 2013 & Yes & No & 75.5 & 62.1 & 19,118 & 3,053 (16) \\
\hline Kuo & 2017 & Canada & Single center & $1995-2014$ & No & No & $72^{\dagger}$ & 63.9 & 215 & $1,520(14)$ \\
\hline Auensen & 2017 & Norway & Single center & $2010-2013$ & No & Yes & 73.0 & 58.0 & 351 & $90(26)$ \\
\hline Total & & - & - & & - & & & & 55,8396 & 111,909 \\
\hline \multicolumn{11}{|l|}{ TAVR } \\
\hline Hannan & 2015 & USA & Single center & 2011-2012 & Yes & No & 81.7 & 46 & 389 & 79 (19) \\
\hline Murughiah $^{\S}$ & 2015 & USA & Multicenter & $2011-2013$ & Yes & No & NR & NR & 14,722 & 3,077 (21) \\
\hline Sawa & 2015 & Japan & Multicenter & $2010-2011$ & No & Yes & 84.3 & 34.4 & 64 & $5(8)$ \\
\hline
\end{tabular}




\begin{tabular}{|c|c|c|c|c|c|c|c|c|c|c|}
\hline Holmes & 2015 & USA & Multicenter & 2011-2013 & No & No & 84.0 & 48.1 & 12,182 & $2,106(17)$ \\
\hline $\begin{array}{l}\text { Nombela- } \\
\text { Franco }\end{array}$ & 2015 & Spain & Multicenter & NR & Yes & Yes & 82.0 & 41.8 & 720 & $105(15)$ \\
\hline Ailawadi & 2016 & USA & Multicenter & 2011-2013 & No & No & 81.0 & 48.0 & 340 & $45(13)$ \\
\hline Panaich & 2016 & USA & Multicenter & 2013 & Yes & No & 83.8 & 50.4 & 12,110 & $2,757(23)$ \\
\hline Noad & 2016 & $\begin{array}{l}\text { N. } \\
\text { Ireland }\end{array}$ & Single center & 2013-2014 & No & Yes & 82.9 & 41.9 & 120 & $6(5)$ \\
\hline Zweng & 2016 & Australia & Single center & 2009-2015 & No & No & 82.3 & 41.0 & 44 & $4(9)$ \\
\hline $\mathrm{Wu}$ & 2016 & $\begin{array}{l}\text { New } \\
\text { Zealand }\end{array}$ & Single center & 2011-2015 & No & No & 80.7 & 57 & 83 & $22(27)$ \\
\hline Harvey & 2016 & USA & Multicenter & 2014 & Yes & No & NR & NR & 8,073 & $1,372(17)$ \\
\hline Eide & 2016 & Norway & Single center & 2011-2013 & Yes & Yes & NR & NR & 63 & $13(21)$ \\
\hline Lauck & 2016 & Canada & Single center & $2012-2014$ & No & No & 81.5 & 60.6 & 393 & $42(11)$ \\
\hline Veijpongsa & 2017 & USA & Multicenter & 2013 & Yes & No & 82.3 & 49.7 & 4,902 & $888(18)$ \\
\hline Sud & 2017 & Canada & Multicenter & $2007-2014$ & Yes & No & 84 & 58 & 709 & $96(14)$ \\
\hline Czarnecki & 2017 & Canada & Multicenter & $2007-2013$ & No & No & $84^{\dagger}$ & 54.6 & 999 & $180(18)$ \\
\hline Dodson & 2017 & USA & Multicenter & 2011-2015 & Yes & No & $84^{\dagger}$ & 51.4 & 18,568 & $3,324(18)$ \\
\hline Forcillo & 2017 & USA & Single center & $2007-2015$ & Yes & No & NR & 53.5 & 714 & $74(10)$ \\
\hline Khera & 2017 & USA & Multicenter & 2016 & Yes & No & 81.2 & 53.8 & 16,252 & $2,665(16)$ \\
\hline McNeely & 2017 & USA & Multicenter & 2011-2013 & No & No & $84^{\dagger}$ & 50.9 & 18,283 & $4,333(24)$ \\
\hline Total & & - & - & & - & & & & 109,730 & 21,193 \\
\hline
\end{tabular}

* Primary endpoint is 30-day all-cause readmission rate after surgical or transcatheter aortic valve replacement (SAVR or TAVR), ${ }^{\dagger}$ Median age, ${ }^{\ddagger} \mathrm{Abstract}$,

${ }^{\S}$ Letter 
Online Table 2. Search strings used for database searches.

\begin{tabular}{|c|c|}
\hline Database & String \\
\hline $\begin{array}{l}\text { Cochrane Library (Cochrane } \\
\text { Reviews, Other Reviews, } \\
\text { Technology Assessment, } \\
\text { Economic Evaluations) }\end{array}$ & $\begin{array}{l}\text { (readmi* or re-admi* or rehosp* or re-hosp* or (admi* and (repeat* or subseq*))) and (aort* or avr or tavr or } \\
\text { pavr or savr or tavi): in Title, Abstract, Keyword } \\
\text { Search } \\
\text { (readmi* or re-admi* or rehosp* or re-hosp* or (admi* and (repeat* or subseq*))) and (card* or heart* or } \\
\text { coronar*): in Title, Abstract, Keyword }\end{array}$ \\
\hline Medline & $\begin{array}{l}\text { Search } \\
\text { ("Heart Valve Prosthesis Implantation"[Mesh] OR "Transcatheter Aortic Valve Replacement"[Mesh] OR } \\
\text { "Heart Valve Prosthesis/surgery"[Mesh] OR "Heart Valve Diseases/surgery"[ Mesh:NoExp] OR "Aortic } \\
\text { Valve Insufficiency/surgery"[Mesh] OR "Aortic Valve Stenosis/surgery"[Mesh] OR "Heart } \\
\text { Valves/surgery"[Mesh:NoExp] OR "Aortic Valve/surgery"[Mesh] OR avr OR tavr OR pavr OR savr OR tavi } \\
\text { OR ((aorta OR aortic) AND valve AND (replacement[ti] OR surgery[ti] OR implant*[ti]))) AND ("Patient } \\
\text { Readmission"[Mesh] OR readmi* OR re-admi* OR rehospital* OR re-hospital* OR "subsequent admission" }\end{array}$ \\
\hline
\end{tabular}




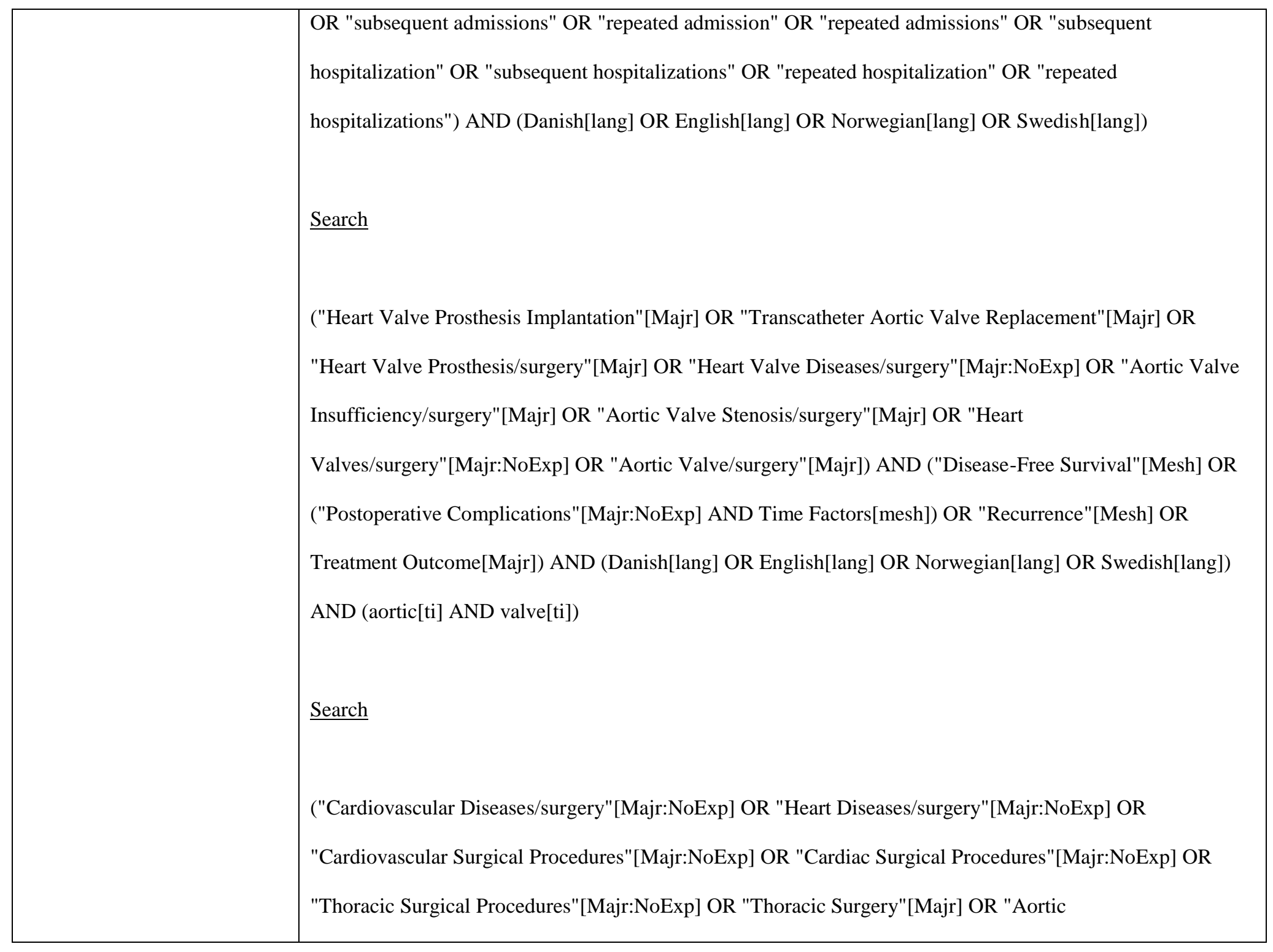




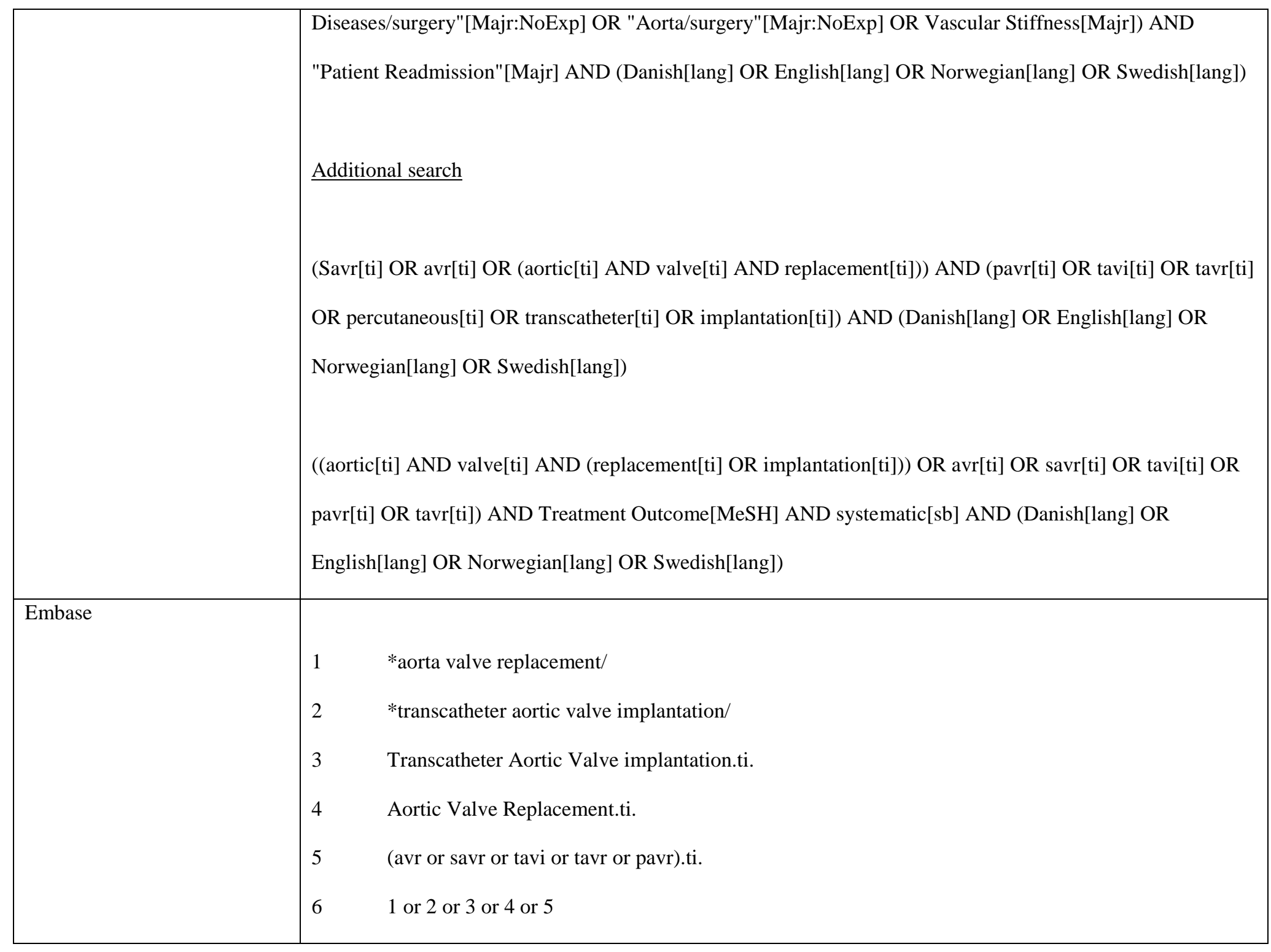




\begin{tabular}{|c|c|c|c|}
\hline & 10 & \multicolumn{2}{|c|}{$\begin{array}{l}\text { *hospital readmission/ } \\
\text { (readmi* or re-admi* or rehospital* or re-hospital*).ti. } \\
7 \text { or } 8 \\
6 \text { and } 9\end{array}$} \\
\hline SweMed & 1 & $\mathrm{ex}$ & $\begin{array}{l}\text { eart Valve Prosthesis Implantation" } \\
\text { Transcatheter Aortic Valve Replacement } \\
\text { Transcatheter Aortic Valve implantation } \\
\text { exp:"Heart Valve Diseases/surgery" } \\
\text { exp:"Aortic Valve Insufficiency/surgery" } \\
\text { exp:"Aortic Valve Stenosis/surgery" } \\
\text { exp:"Heart Valves/surgery" } \\
\text { exp:"Aortic Valve/surgery" } \\
\text { \#1 OR \#2 OR \#3 OR \#4 OR \#5 OR \#6 OR \#7 OR \#8 } \\
\text { exp:"Patient Readmission" } \\
\text { Readmission* } \\
\text { rehospital* } \\
\text { reinnlegg* } \\
\text { \#10 OR \#11 OR \#12 OR \#13 } \\
\text { \#9 AND \#14 }\end{array}$ \\
\hline
\end{tabular}




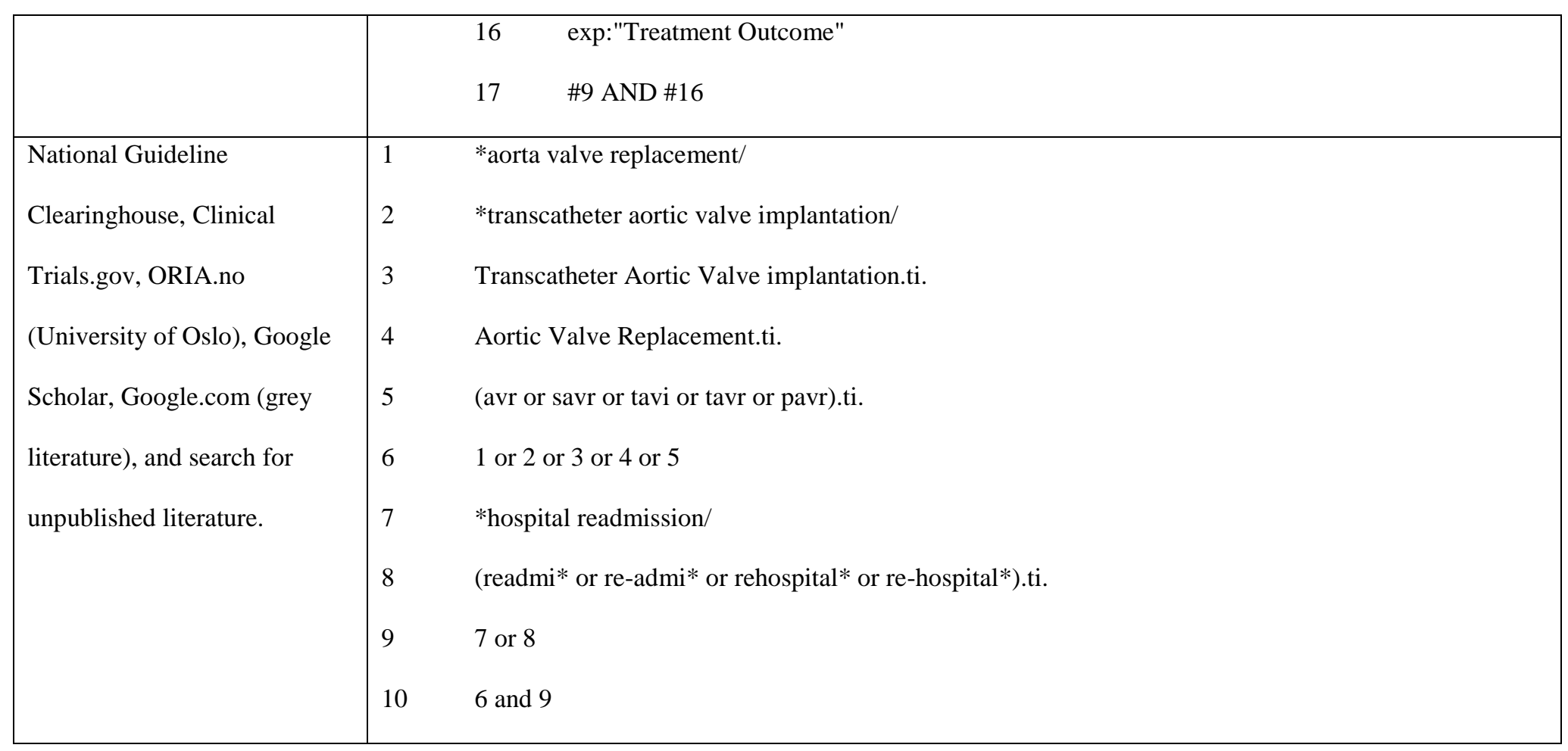


Online Table 3. Quality assessment of included articles based on the Newcastle-Ottawa Scale (NOS).

\begin{tabular}{|c|c|c|c|c|c|c|c|c|c|c|c|}
\hline \multirow{2}{*}{$\begin{array}{l}\text { Study } \\
\text { SAVR }\end{array}$} & \multirow[t]{2}{*}{ Year } & \multicolumn{4}{|c|}{ Selection } & \multicolumn{2}{|c|}{ Comparability } & \multicolumn{3}{|c|}{ Exposure } & \multirow{2}{*}{$\begin{array}{l}\text { No. of } \\
\text { stars* }\end{array}$} \\
\hline & & S1 & $\mathrm{S} 2$ & S3 & S4 & $\mathrm{C} 1$ & $\mathrm{C} 2$ & E1 & E2 & E3 & \\
\hline Brown & 2008 & $*$ & NR & $*$ & - & NR & NR & $*$ & $*$ & - & $4 / 6$ \\
\hline Lancaster & 2013 & $*$ & NR & $*$ & - & NR & NR & $*$ & $*$ & - & $4 / 6$ \\
\hline Barreto-Filho & 2013 & $*$ & NR & $*$ & - & NR & NR & $*$ & $*$ & - & $4 / 6$ \\
\hline Hannan & 2015 & $*$ & NR & $*$ & - & NR & NR & $*$ & $*$ & - & $4 / 6$ \\
\hline Murughiah & 2015 & $*$ & NR & $*$ & - & NR & NR & $*$ & $*$ & - & $4 / 6$ \\
\hline Redzek & 2015 & $*$ & NR & $*$ & $*$ & NR & NR & $*$ & $*$ & - & $5 / 6$ \\
\hline Arora & 2016 & - & - & - & - & - & - & - & - & - & - \\
\hline Zweng & 2016 & $*$ & NR & $*$ & - & NR & NR & $*$ & $*$ & - & $4 / 6$ \\
\hline McNeely & 2016 & $*$ & NR & $*$ & - & NR & NR & $*$ & $*$ & - & $4 / 6$ \\
\hline Vejpongsa & 2017 & $*$ & NR & $*$ & - & NR & NR & $*$ & $*$ & - & $4 / 6$ \\
\hline Kuo & 2017 & $*$ & NR & $*$ & - & NR & NR & $*$ & $*$ & - & $4 / 6$ \\
\hline Auensen & 2017 & $*$ & $*$ & $*$ & $*$ & $*$ & - & $*$ & $*$ & $*$ & $8 / 9$ \\
\hline TAVR & & & & & & & & & & - & \\
\hline Hannan & 2015 & $*$ & NR & $*$ & - & NR & NR & $*$ & $*$ & - & $4 / 6$ \\
\hline Murughiah & 2015 & - & - & - & - & - & - & - & - & - & - \\
\hline
\end{tabular}




\begin{tabular}{|c|c|c|c|c|c|c|c|c|c|c|c|}
\hline Sawa & 2015 & * & NR & * & * & NR & NR & * & * & - & $5 / 6$ \\
\hline Holmes & 2015 & * & NR & * & - & NR & NR & * & $*$ & - & $4 / 6$ \\
\hline Nombela-Franco & 2015 & $*$ & NR & * & * & NR & NR & $*$ & * & * & $6 / 6$ \\
\hline Ailawadi & 2016 & * & NR & * & - & NR & NR & * & * & - & $4 / 6$ \\
\hline Panaich & 2016 & $*$ & NR & $*$ & - & NR & NR & $*$ & * & - & $4 / 6$ \\
\hline Noad & 2016 & $*$ & NR & $*$ & $*$ & NR & NR & $*$ & * & * & $6 / 6$ \\
\hline Zweng & 2016 & $*$ & NR & $*$ & - & NR & NR & $*$ & * & - & $4 / 6$ \\
\hline $\mathrm{Wu}$ & 2016 & $*$ & NR & $*$ & - & NR & NR & $*$ & $*$ & - & $4 / 6$ \\
\hline Harvey & 2016 & - & - & - & - & - & - & - & - & - & - \\
\hline Eide & 2016 & $*$ & NR & $*$ & $*$ & NR & NR & $*$ & * & * & $6 / 6$ \\
\hline Lauck & 2016 & $*$ & NR & $*$ & - & NR & NR & $*$ & * & * & $5 / 6$ \\
\hline Vejpongsa & 2017 & $*$ & NR & $*$ & - & NR & NR & $*$ & $*$ & - & $4 / 6$ \\
\hline Sud & 2017 & * & NR & * & - & NR & NR & $*$ & * & - & $4 / 6$ \\
\hline Czarnecki & 2017 & * & NR & * & - & NR & NR & * & * & - & $4 / 6$ \\
\hline Dodson & 2017 & $*$ & NR & $*$ & - & NR & NR & $*$ & $*$ & - & $4 / 6$ \\
\hline Forcillo & 2017 & $*$ & NR & $*$ & - & NR & NR & $*$ & $*$ & * & $5 / 6$ \\
\hline Khera & 2017 & $*$ & NR & $*$ & - & NR & NR & $*$ & * & - & $4 / 6$ \\
\hline McNeely & 2017 & * & NR & $*$ & - & NR & NR & $*$ & * & - & $4 / 6$ \\
\hline
\end{tabular}


"No. of stars given= relevant score possibility; S1, How representative is the exposed cohort?; S2, Selection of the non-exposed cohort?; S3, Ascertainment of exposure?; S4,

Outcome not present at start of study?; C1, Comparability of readmission outcome?; C2, Comparability of the design?; E1, Assessment of outcome?; E2, Sufficiently long follow-up for outcome to occur?; E3, Adequacy of follow-up?; NR=Not relevant 
Online Table 4. Cause for 30-day all-cause readmission after surgical aortic valve replacement (SAVR).

\begin{tabular}{|c|c|c|c|}
\hline Causes for readmission & Hannan 2015 (\%) & McNeely 2016 (\%) & Vejpongsa 2017 (\%) \\
\hline Heart failure (HF) & 19.2 & 18.2 & 15.3 \\
\hline Cardiac rhythm disorder & 9.6 & & 13.7 \\
\hline Stroke or TIA & 5.5 & & \\
\hline Pneumonia & 5.5 & & \\
\hline Pneumothorax, pleural effusion & 5.5 & & \\
\hline GI Bleeding & 5.5 & & 3.1 \\
\hline GI Problems & & & 6.9 \\
\hline Respiratory failure & 4.1 & & \\
\hline Respiratory & & & 13.6 \\
\hline Sepsis & 2.7 & & \\
\hline Postoperative infection & 2.7 & & 7.3 \\
\hline AMI & 1.4 & & \\
\hline Hemorrhage or hematoma & 0 & & \\
\hline $\begin{array}{l}\text { Noninflammatory complication of } \\
\text { cardiac device or implant }\end{array}$ & 0 & & \\
\hline Surgical complication & & & 14.7 \\
\hline
\end{tabular}


Online Table 5. Causes for all-cause 30-day readmission after TAVR.

\begin{tabular}{|c|c|c|c|c|c|c|c|c|c|}
\hline Causes & $\begin{array}{l}\text { Nombela- } \\
\text { Franco } \\
2015\end{array}$ & $\begin{array}{l}\text { Hannan } \\
2015\end{array}$ & $\begin{array}{l}\text { Murugiha } \\
2015\end{array}$ & $\begin{array}{l}\text { Panaich } \\
2016\end{array}$ & $\begin{array}{l}\text { Kolte } \\
2016\end{array}$ & $\begin{array}{l}\text { Vejpongsa } \\
2017\end{array}$ & Khera 2017 & $\begin{array}{l}\text { Forcillo } \\
2017\end{array}$ & $\begin{array}{l}\text { McNeely } \\
2017\end{array}$ \\
\hline $\mathrm{HF}$ & $30.4 \%$ & $21,9 \%$ & $4.8 \%$ & $22.38 \%$ & $22.5 \%$ & $20.7 \%$ & $\begin{array}{l}\text { 1. cardiac } \\
\text { cause }\end{array}$ & $25.7 \%$ & $25.7 \%$ \\
\hline Conduction disorders & & & & & & & $\begin{array}{l}\text { 4. cardiac } \\
\text { cause }\end{array}$ & & \\
\hline Acute coronary syndrome & $1,7 \%$ & 0 & & & & & & & \\
\hline Respiratory incl. Pneumonia & & & & & $14.6 \%$ & & & & \\
\hline Infection & $10.4 \%$ & $11 \%$ & & $12.78 \%$ & $12.9 \%$ & $7.3 \%$ & $\begin{array}{l}\text { 3.non-cardiac } \\
\text { cause }\end{array}$ & & \\
\hline Bleeding & $8.7 \%$ & & & $15.84 \%$ & & & $\begin{array}{l}\text { 4.non-cardiac } \\
\text { cause }\end{array}$ & & \\
\hline
\end{tabular}


Peripheral vascular event

$6.1 \%$

Cerebrovascular event

Traumatology

Strok or TIA

Pneumonia

Pneumothorax, pleural effusion

GI Bleeding

Respiratory failure

Sepsis

Hemorrhage or hematoma

Noninflammatory complication of

cardiac device or implant

Postoperative complications (shock,

hematoma, wound dehiscence and

infection)

Mechanical device complication

Kidney/Urinary complication

Surgical complication

$5.2 \%$
$5.08 \%$

$1.4 \%$
$1.4 \%$

$0.5 \%$ 
Gastrointestinal problems

Valve disorders
$8.8 \%$

5. non-cardiac

cause

3. cardiac

cause 
Online Table 6. Risk factors of 30-day all-cause readmission rate after transcatheter aortic valve replacement (TAVR).

\begin{tabular}{|c|c|c|c|c|c|c|}
\hline & $\begin{array}{l}\text { Nombela- } \\
\text { Franco } 2015\end{array}$ & Panaich 2016 & Harvey 2016 & Kolte 2017 & Dodson 2017 & Forcillo 2017 \\
\hline Risk factor & OR & OR & OR & HR & OR & HR \\
\hline $\begin{array}{l}\text { Major/life threatening } \\
\text { bleeding }\end{array}$ & $2.41(1.57-3.70)$ & & & & & \\
\hline $\begin{array}{l}\text { LVEF at hospital } \\
\text { discharge }\end{array}$ & $1.08(1.00-1.17)$ & & & & & \\
\hline $\mathrm{Hb}$ at hospital discharge & $1.19(1.03-1.39)$ & & & & & \\
\hline $\begin{array}{l}\text { Single or dual } \\
\text { antiplatelet therapy }\end{array}$ & $1.62(1.10-2.39)$ & & & & & \\
\hline Trans apical & & $1.23(1.10-1.38)$ & & $\begin{array}{l}1.21(1.05- \\
1.39)\end{array}$ & $1.43(1.31-1.57)$ & \\
\hline Diabetes & & $1.18(1.06-1.32)$ & & & $1.13(1.04-1.23)$ & \\
\hline Chronic lung disease & & $1.32(1.18-1.47)$ & $1.18(1.03-1.34)$ & $\begin{array}{l}1.16(1.01- \\
1.34)\end{array}$ & $1.22(1.21-1.33)$ & \\
\hline Renal failure & & $1.43(1.24-1.65)$ & & & & \\
\hline Facility/others & & $1.28(1.14-1.42)$ & $1.30(1.10-1.53)$ & $\begin{array}{l}1.16(1.01- \\
1.34)\end{array}$ & & \\
\hline
\end{tabular}


Length of stay, primary

admission:

3 to 6 days

$1.76(1.31-2.76)$

7 to 10 days

$2.32(1.70-3.17)$

$>10$ days

$3.06(2.22-4.22)$

2 prior admissions in

$2.33(2.02-2.70)$

year before TAVI

History of dialysis

$1.78(1.26-2.51)$

$1.76(1.24-2.49)$

$1.47(1.13-1.89)$

$1.73(1.14-2.61)$

Blood loss

$0.78(0.62-0.99)$

Anemia

New onset atrial

$1.70(1.24-2.49)$

fibrillation

Baseline atrial

$1.46(1.29-1.66)$

fibrillation

Atrial fibrillation/Flutter

$1.26(1.17$

1.36)

1 prior admission in

$1.65(1.41-1.92)$

year before TAVI 
Acute kidney injury

Chronic kidney disease

Baseline atrial

fibrillation

Paroxysmal tachycardia

Respiratory failure

Length of stay $>5$ days

$>4$ Elixhauser

comorbidities

In-hospital vascular

complication

Transfusion

Glomerular filtration

rate $(<30$ vs $\geq 30)$
$1.62(1.36-1.94) \quad 1.23(1.05-$

1.44)

$1.20(1.04-$

1.39)

$1.46(1.29-1.66)$

$1.38(1.07-1.77)$

$1.25(1.01-1.55)$

$1.47(1.24-$

1.73)

$1.22(1.03-$

1.46)

$1.34(1.18-1.53)$

$1.30(1.19-1.42)$

$1.33(1.14-1.56)$ 
Glomerular filtration

rate (On dialysis vs

$\geq 30)$

Hours in Intensive Care

Unit

Prior cardiac surgery (1

vs 0)

Female

NYHA

(moderate/severe)

Age

Mitral insufficiency

(moderate/severe)
$0.85(0.77-0.94)$

$1.61(1.34-1.93)$

$1.00(1.00-1.00)$

$0.91(0.84-0.99)$

$1.12(1.00-1.25)$

$1.00(1.00-1.01)$

$1.08(1.00-1.18)$ 
Online Figure 1. Analysis of publication bias by Funnel plots of studies of included articles for surgical and transcatheter aortic valve replacement

(SAVR and TAVR).

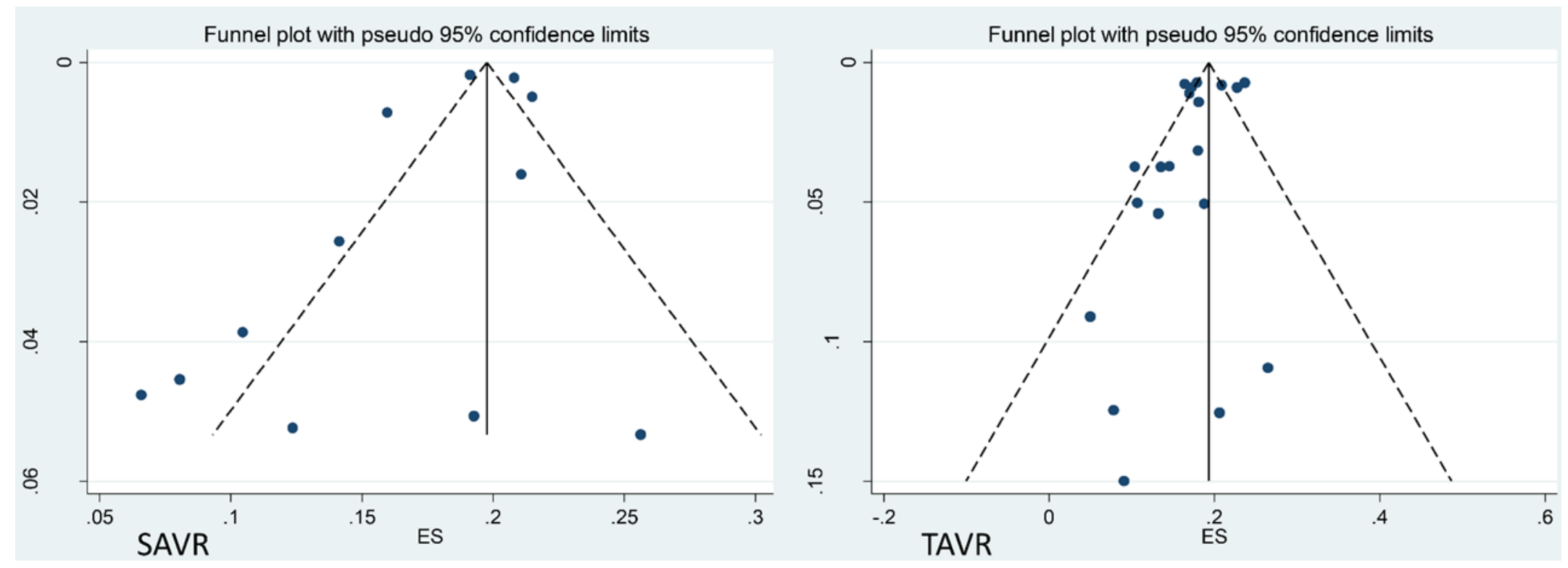


